\title{
A New Approach for Reliability Life Prediction of Rail Vehicle Axle by Considering Vibration Measurement
}

\author{
Meral Bayraktar, Rahmi Guclu, and Necati Tahrali \\ Department of Mechanical Engineering, Mechanical Engineering Faculty, Yildiz Technical University, Besiktas, 34349 Istanbul, Turkey \\ Correspondence should be addressed to Meral Bayraktar; mbarut@yildiz.edu.tr
}

Received 13 May 2014; Accepted 19 September 2014; Published 8 October 2014

Academic Editor: Francesco Braghin

Copyright (C) 2014 Meral Bayraktar et al. This is an open access article distributed under the Creative Commons Attribution License, which permits unrestricted use, distribution, and reproduction in any medium, provided the original work is properly cited.

\begin{abstract}
The effect of vibration on the axle has been considered. Vibration measurements at different speeds have been performed on the axle of a running rail vehicle to figure out displacement, acceleration, time, and frequency response. Based on the experimental works, equivalent stress has been used to find out life of the axles for $90 \%$ and $10 \%$ reliability. Calculated life values of the rail vehicle axle have been compared with the real life data and it is found that the life of a vehicle axle taking into account the vibration effects is in good agreement with the real life of the axle.
\end{abstract}

\section{Introduction}

The critical areas on the wheelset and axle are generally all press-fits (e.g., the wheel seat, the brake disc seat, the bearing seat, the labyrinth seal seat, and the drive pinion seat for driven axles) as well as the axle fillet radii [1].

Dynamic simulation can be used as a source of information on load cases for parts of the vehicle structure [2, $3]$. This is one of the more challenging applications for simulation because it often concerns parts of the structure such as the bogie frame or wheelsets where higher frequencies are important and because extreme events can be an important consideration. When developing simulation models for structural analysis is particularly important in which structural flexibilities should be considered, at least up to the maximum frequency is considered important [4].

The interactions of structural and vehicle system dynamics with respect to fatigue life calculations on condition of short computation times have been reported by [5]. As the vehicle operation and the dynamical behaviour of the vehicle are taken into account, the reliability of fatigue life calculation of vehicle components is significantly improved by the strategy proposed. The new method enables comparing different designs of the bogie frame and helps to obtain an optimum structural design, especially when new technologies are requested.
Lee et al. [6] have performed the fatigue analysis of high speed passenger train which has been designed for maximum speed of $350 \mathrm{~km} / \mathrm{h}$ by considering aerodynamic forces. In the case of cross running inside a tunnel, fatigue damage has been significantly greater, but the criteria of fatigue strength evaluation by the modified Goodman diagram have been satisfied.

Locovei et al. [7] have focused on the fracture mechanism of railway axles due to fatigue of material. They aimed to predict the number of cycles (in $\mathrm{km}$ ) to fracture of tank wagon railway axle in various theoretical conditions by simulating the loads and stresses. It has been seen that the fracture of the axles has occurred in the area of most intense stresses, below the locking ring of the bearing. Despite the fracture, the wagon continued to run with all the load of the axle supported by the bearing box. Therefore, the heat produced by the intense friction of the axle and the locking ring against the bearing box caused the melting of the locking ring and ultimately of the bearing box. The chain of phenomena has resulted as deformation and fracture of bearing box.

A limiting factor in high speed rail vehicles is the dynamic phenomenon called hunting which initially becomes apparent as a lightly damped lateral/yaw response of the vehicle. Due to its importance to the operation of the vehicles hunting has been studied for several decades. Subsequent studies have 

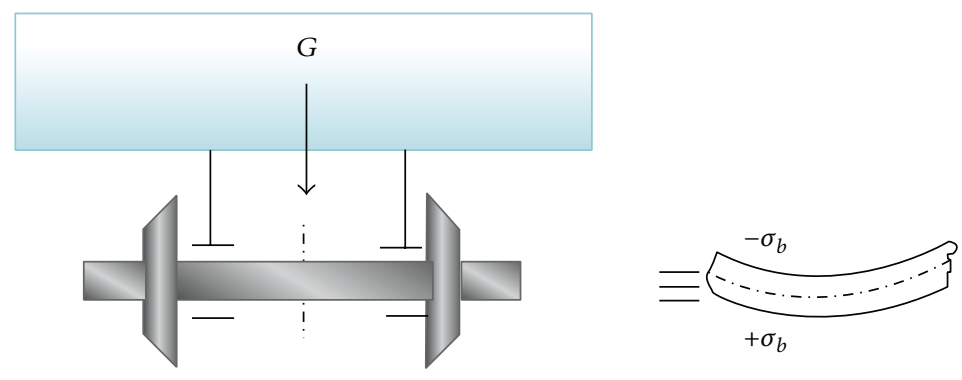

FIGURE 1: Fully reversed loading.

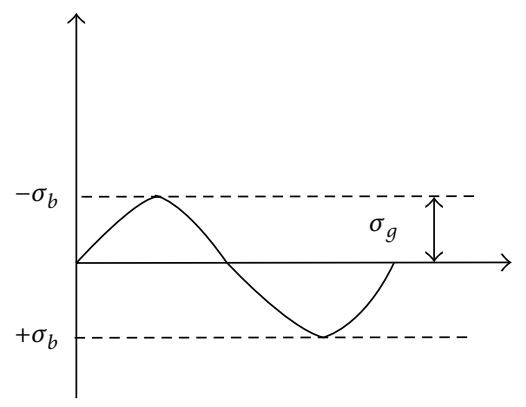

FiGuRe 1: Fully reversed loading.

extended the linear models to include the nonlinear aspects of the system [8-10].

Watson and Timmis [11] explained factors influencing axle stresses as axle load, curve radius, cant deficiency, track roughness, running in depots, high frequency bending behavior, torsional axle strain, discrete track irregularities, wheel flats, wheel out-of-roundness, wheelset and bogie configuration, passenger load spectrum, weather, braking, position of axle in train, and long term changes. For solid axles, even if the operating stresses are significantly below design limits, very little useful weight reduction can be achieved by reducing the diameter to increase the stress to the allowable limit. Axle strain cycles at a frequency greater than $20 \mathrm{~Hz}$ (the maximum wheel turning frequency) have been performed in the axle tests.

Reasons of railway traction shafts and axles fracture have been investigated by Ognjanovic et al. [12]. Natural vibrations of railway wheels caused by the stick-sleep process in the wheel-rail contact and the fracture of the bearing and the shaft-axle braking have been presented. Possible preventions against traction shafts (axles) fracture were suggested. Significant stress concentration occurred at the area between the wheel and traction gear.

Fatigue tests of produced railway axles have been performed by Novosad et al. [13] and results were compared with tests on small specimens and demands of railway standards. The procedures for design and calculation of the axles such as fatigue limit and safety factor of the axle are defined by European standards EN 13103 [14] and EN13104 [15]. All these measurements and calculations showed effort of railway axles producers that aim at higher safety and better fatigue properties of railway axles.

In the present paper, the axle failures which occurred on rail vehicles of Istanbul Transportation Co. have been examined. It was seen that the axles damaged during service due to different reasons such as bad conditions of track and overloading. It should be noted that the axles have been used in both bogie of a tramway (TR) and a light rail vehicle (LRT). Details of the axles can be found in Table 1.

In the previous study [16] by assuming the vehicles run under the idealized conditions, the logarithmic life equations for the cases of TR and TR-LRT have been derived by means of the real fracture data. However, the vibration effects have been ignored while deriving the life equations of the axles. The effects of vibration on the life of axles have been considered in the present work. To reveal the negative effects of vibration, the vibration measurements at different speeds $(30 \mathrm{~km} / \mathrm{h}, 40 \mathrm{~km} / \mathrm{h}$, and $50 \mathrm{~km} / \mathrm{h})$ have been performed on axle of a running rail vehicle. Such measurements enable determining the displacement, acceleration, time, and frequency response. The measured data have been used for the calculation of new equivalent stress including additional bending stress born by vibration. In the light of obtained new equivalent stress, the life of the axle has been presented by $10 \%$ and $90 \%$ reliability. Finally, obtained results have been compared with the real life values (Table 1).

\section{Stress Analysis}

It is a fact that most machinery and many structures do not operate under a constant load and stress due to constantly changing conditions. Rotating shafts such as the axle on rail vehicle are an important example. When the axle rotates $180^{\circ}$, bending stresses change from tension to compression or vice versa.

The axle which runs at $80 \mathrm{~km} / \mathrm{h}$ and rotates $663 \mathrm{RPM}$ is exposed to stresses which show a periodic alteration between positive and negative values (Figure 1). Such stress that varies periodically causes fatigue fracture in the structures as shown in Figure 1.

2.1. Palmgren-Miner Cumulative Damage Theory. Ever since Wohler discussed the railway wagon axle failures in fatigue, this subject gained importance in the design of machinery. The strength of material under the action of completely reversed stress fatigue loads is determined from $S-N$ diagrams. These diagrams are not representative of an actual machine member and therefore the fatigue strength is to be modified to take into account the conditions prevailing for a specific machine subjected to fatigue [17].

Fatigue damage increases with applied load cycles in a cumulative manner. Cumulative fatigue damage analysis plays a key role in life prediction of components and structures subjected to field load histories. The first cumulative damage theory was applied by A. Palmgren for predicting the life of roller bearings in 1920 in Sweden. B. F. Langer followed him in general form. However, the theory was not known and used until it occurred in M. A. Miner's study in 1945. Since 
TABLE 1: Life values in $\mathrm{km}$ [16].

\begin{tabular}{|c|c|c|c|c|c|c|}
\hline & & $\mathrm{B}$ & $\mathrm{C}$ & $\mathrm{D}$ & $\mathrm{E}$ & $\mathrm{F}$ \\
\hline \multirow{14}{*}{ LRT $100.000 \mathrm{Km}$} & \multirow{14}{*}{ TR $18.000 \mathrm{Km}$} & 513 & 08.06.1997 & 378.800 & TR & TR \\
\hline & & 529 & 22.08 .1997 & 360.000 & TR & TR \\
\hline & & 532 & 25.11.1997 & 380.000 & TR & TR \\
\hline & & 533 & 24.03.1998 & 390.167 & TR & TR \\
\hline & & 557 & 14.09 .1998 & 332.761 & TR & TR \\
\hline & & 514 & 11.10 .1998 & 446.000 & TR & TR \\
\hline & & 517 & 12.05 .1999 & 507.500 & $\mathrm{TR}$ & TR \\
\hline & & 513 & 08.06.1999 & 499.064 & TR & TR \\
\hline & & 517 & 11.11.1999 & 543.750 & TR & TR \\
\hline & & 526 & 14.12.1999 & 545.630 & TR & TR \\
\hline & & 529 & 26.10 .2000 & 571.701 & TR & TR \\
\hline & & 530 & 04.01.2001 & 622.000 & TR & $\mathrm{TR}$ \\
\hline & & 105 & 18.04 .2001 & 510.300 & $\mathrm{TR}$ & TR \\
\hline & & 536 & 03.09 .2002 & 1.032 .000 & LRT & LRT \\
\hline \multirow{6}{*}{ LRT $30.000 \mathrm{Km}$} & \multirow{6}{*}{ TR 18.000} & 504 & 07.02 .2003 & 761.000 & TR & TR \\
\hline & & 503 & 06.10 .2003 & 821.000 & TR & $\mathrm{TR}$ \\
\hline & & 101 & 24.12.2004 & 612.525 & LRT & TR \\
\hline & & 561 & 16.03 .2005 & 1.289 .000 & LRT & TR \\
\hline & & 560 & 06.05 .2005 & 1.291 .000 & LRT & TR \\
\hline & & 101 & 20.05 .2005 & 659.708 & LRT & TR \\
\hline \multirow{27}{*}{ LRT $10.000 \mathrm{Km}$} & \multirow{27}{*}{ TR $6.000 \mathrm{Km}$} & 530 & 24.05 .2005 & 866.500 & LRT & TR \\
\hline & & 558 & 24.05 .2005 & 813.500 & LRT & $\mathrm{TR}$ \\
\hline & & 131 & 24.05 .2005 & 1.234 .377 & LRT & TR \\
\hline & & 107 & 16.06 .2005 & 1.261 .298 & LRT & TR \\
\hline & & 525 & 06.09.2005 & 901.279 & LRT & TR \\
\hline & & 520 & 21.09 .2005 & 871.800 & LRT & $\mathrm{TR}$ \\
\hline & & 520 & 21.09 .2005 & 871.800 & LRT & $\mathrm{TR}$ \\
\hline & & 111 & 02.12 .2005 & 1.276 .400 & LRT & TR \\
\hline & & 556 & 07.02 .2006 & 1.404 .655 & LRT & TR \\
\hline & & 514 & 24.02 .2006 & 879.239 & LRT & TR \\
\hline & & 560 & 05.05 .2006 & 1.391 .275 & LRT & TR \\
\hline & & 517 & 26.07.2006 & 950.000 & LRT & $\mathrm{TR}$ \\
\hline & & 107 & 09.11.2006 & 1.471 .441 & LRT & TR \\
\hline & & 565 & 06.01 .2007 & 1.501 .000 & LRT & TR \\
\hline & & 116 & 12.01.2007 & 1.443 .922 & LRT & TR \\
\hline & & 555 & 12.01 .2007 & 1.485 .698 & LRT & TR \\
\hline & & 111 & 15.01.2007 & 1.381 .371 & LRT & TR \\
\hline & & 111 & 25.01.2007 & 1.384 .576 & LRT & TR \\
\hline & & 507 & 29.01.2007 & 861.627 & LRT & TR \\
\hline & & 507 & 29.01.2007 & 861.627 & LRT & TR \\
\hline & & 510 & 19.04.2007 & 859.917 & LRT & TR \\
\hline & & 503 & 17.05 .2007 & 893.314 & LRT & TR \\
\hline & & 132 & 31.05 .2007 & 1.439 .114 & LRT & TR \\
\hline & & 523 & 04.07.2007 & 1.000 .286 & LRT & TR \\
\hline & & 505 & 15.08 .2007 & 945.487 & LRT & TR \\
\hline & & 524 & 19.09 .2007 & 1.256 .356 & LRT & TR \\
\hline & & 520 & 04.09.2007 & 1.082 .673 & LRT & TR \\
\hline
\end{tabular}

A: ultrasonic inspection period.

B: vehicle number.

C: date.

D: Km.

E: where the failure has occurred (TR/LRT).

F: where the axle has run before. 


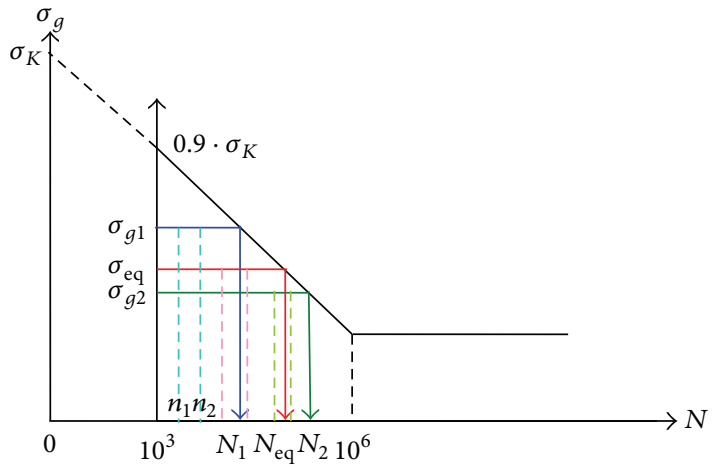

FIGURE 2: Spectrum loading for total life " $N$ " and load cycles " $n$ " corresponding to different stress amplitudes [21].

then the treatment of cumulative fatigue damage has received increasingly more attention. This linear theory is known as the Palmgren-Miner hypothesis or the linear damage rule [18-20]. It is based on the $S-N$ graphic shown in Figure 2 [21]. Operation at a stress level $\sigma_{1}$ gives a life of $N_{1}$ cycles. If the element is subjected to $n_{1}$, it suffers a damage fraction $D_{i}=n_{i} / N_{i}$. Failure is then predicted to take place where $\sum\left(n_{i} / N_{i}\right) \geq 1$.

It asserts that the damage fraction at any stress level is linearly proportional to the number of cycles that would produce failure at that stress level. As the element is subjected to a mean stress, the $S-N$ plane is shifted to the location of the applied mean stress level on the fatigue failure surface.

One of the serious drawbacks of this theory is that it does not recognize the order of application of various stress levels and damage is assumed to accumulate at the same rate at a given stress level without a consideration of the past history. Experimental evidence shows that fatigue damage accumulates nonlinearly, depending on the alternating stress level [22]. If different cycle stress amplitudes are mixed randomly, Miner's total damage approximates 1 . Generally the use of this theory is satisfactory because the stresses in many applications involve various descents and ascents. According to Palmgren-Miner theory when the summation of cycle rates reaches $K$ (which means the life exhausted 100\%) fatigue damage occurs as stated mathematically in (1).

Consider

$$
\frac{n_{1}}{N_{1}}+\frac{n_{2}}{N_{2}}+\frac{n_{3}}{N_{3}}+\cdots+\frac{n_{i}}{N_{i}}=K
$$

where $n_{1}, n_{2}, \ldots, n_{i}$ are the number of load cycles at a specific stress level such as $\sigma_{1}, \sigma_{2}, \ldots, \sigma_{i}$ and $N_{1}, N_{2}, \ldots, N_{i}$ represent the fatigue life in cycles at the same stress level. $K$ is a constant that changes between 0.7 and 2.2 as given by [23].

Determining $n_{1}, n_{2}, \ldots, n_{i}$ is very difficult. If they are stated as the parts of total life $\left(N_{\mathrm{eq}}\right), n_{1}=c_{1} \cdot N_{\mathrm{eq}}, n_{2}=$ $c_{2} \cdot N_{\text {eq }}, \ldots, n_{i}=c_{i} \cdot N_{\text {eq }}$, (2) is derived as given below where $c_{1}, c_{2}, \ldots, c_{i}$ are proportion factors:

$$
\frac{c_{1}}{N_{1}}+\frac{c_{2}}{N_{2}}+\frac{c_{3}}{N_{3}}+\cdots+\frac{n_{i}}{N_{i}}=\frac{1}{N_{\mathrm{eq}}}
$$

The Palmgren-Miner theory will be successful when axle shaft is exposed to different loading cases during its service life. The most important effect for axle life is stresses that act on the axle. These stress values change permanently as a result of passenger loading rates.

In the previous work, Bayraktar et al. [16] found equivalent stress value of the critical section of the axle as $\sigma_{\text {eq }}=$ $220 \mathrm{~N} / \mathrm{mm}^{2}$ in case of different occupancy rates (passenger numbers) for 18 hours which is the service time. Time for taking the curves and additional bending stress related to centrifuge loads had been considered.

\section{Logarithmic Life Equations for the Axles}

Statistical assessments and derivation of the logarithmic life equations are based on normal distribution of fatigue concept. An extensive knowledge on fatigue life can be found in [24]. Equivalent stresses have been obtained by considering the service time and life values given in Tables 2 and 3 statistically. These stress values have been assessed related to statistical distribution function denoted by the following equations. Mean life, standard deviation of life, standard variable for life, standard deviation of stress, and standard variable for stress are given in (3)-(8), respectively:

$$
\begin{gathered}
\bar{N}=\frac{1}{n} \cdot \sum_{i=1}^{n} N_{i}, \\
S_{N}=\left(\sum_{i=1}^{n} \frac{\left(N_{i}-\overline{N_{i}}\right)^{2}}{n-1}\right)^{1 / 2}, \\
N_{i}=\overline{N_{i}}+z_{\alpha} \times S_{N}, \\
\bar{\sigma}=\frac{1}{n} \cdot \sum_{i=1}^{n} \sigma_{i}, \\
S_{\sigma}=\left(\sum_{i=1}^{n} \frac{\left(\sigma_{i}-\overline{\sigma_{i}}\right)^{2}}{n-1}\right)^{1 / 2}, \\
\sigma_{i}=\overline{\sigma_{i}}+z_{\alpha} \times S_{\sigma} .
\end{gathered}
$$

Logarithmic equations have been obtained by considering Wöhler diagram as given in Figure 3.

The equivalent stress value is used to derive the logarithmic life equations given in (9)-(12). These are related to load cycle without the vibration effect for the cases when only TR and TR-LRT are in operation by considering $90 \%$ and $10 \%$ reliability [16].

Derived life equations for $90 \%$ reliability in the case of TR:

$$
\log N=10.1515-7.9462 \frac{\sigma_{g}}{\sigma_{K \max }} .
$$

Derived life equations for $10 \%$ reliability in the case of TR:

$$
\log N=11.1122-9.0136 \frac{\sigma_{g}}{\sigma_{K \min }} .
$$


TABle 2: Case: TR [25].

\begin{tabular}{|c|c|c|c|c|}
\hline Vehicle number & KM & Load cycle $(N)$ & $\log (N)$ & $\log \left(N_{\mathrm{km}}\right)$ \\
\hline 513 & 378800 & 200959641.5 & 8.303109 & 5.57841 \\
\hline 529 & 360000 & 190985931.7 & 8.281001 & 5.556303 \\
\hline 532 & 380000 & 201596261.2 & 8.304482 & 5.579784 \\
\hline 533 & 390167 & 206990022.3 & 8.315949 & 5.591251 \\
\hline 557 & 332761 & 176535193.4 & 8.246831 & 5.522132 \\
\hline 514 & 446000 & 236610348.7 & 8.374034 & 5.649335 \\
\hline 517 & 507500 & 269237112.1 & 8.430135 & 5.705436 \\
\hline 513 & 499064 & 264761675.1 & 8.422855 & 5.698156 \\
\hline 517 & 543750 & 288468334.4 & 8.460098 & 5.735399 \\
\hline 526 & 545630 & 289465705.3 & 8.461597 & 5.736898 \\
\hline 529 & 571701 & 303296800.4 & 8.481868 & 5.757169 \\
\hline 530 & 622000 & 329981248.7 & 8.518489 & 5.79379 \\
\hline 105 & 510300 & 270722558.2 & 8.432524 & 5.707826 \\
\hline 504 & 761000 & 403723039 & 8.606084 & 5.881385 \\
\hline 503 & 821000 & 435554027.6 & 8.639042 & 5.914343 \\
\hline
\end{tabular}

TABLE 3: Case: TR-LRT [25].

\begin{tabular}{|c|c|c|c|c|}
\hline Vehicle number & $\mathrm{Km}$ & Load cycle $(N)$ & $\log (N)$ & $\log \left(N_{\mathrm{km}}\right)$ \\
\hline 561 & 1289000 & 683835590.9 & 8.8349517 & 6.110253 \\
\hline 560 & 1291000 & 684896623.6 & 8.835625025 & 6.110926 \\
\hline 530 & 866500 & 459692427.8 & 8.66246735 & 5.937769 \\
\hline 558 & 813500 & 431575060.6 & 8.63505634 & 5.910358 \\
\hline 131 & 1234377 & 654857195.6 & 8.816146604 & 6.091448 \\
\hline 107 & 1261298 & 669139226.6 & 8.82551649 & 6.100818 \\
\hline 525 & 901279 & 478143256.4 & 8.679558035 & 5.954859 \\
\hline 520 & 871800 & 462504164.6 & 8.665115648 & 5.940417 \\
\hline 520 & 871800 & 462504164.6 & 8.665115648 & 5.940417 \\
\hline 111 & 1276400 & 677151084.7 & 8.830685578 & 6.105987 \\
\hline 556 & 1404655 & 745192460.7 & 8.872268452 & 6.14757 \\
\hline 514 & 879239 & 466450675.8 & 8.668805727 & 5.944107 \\
\hline 560 & 1391275 & 738094151.8 & 8.868111764 & 6.143413 \\
\hline 517 & 950000 & 503990544.1 & 8.702422388 & 5.977724 \\
\hline 107 & 1471441 & 780623526.5 & 8.892441636 & 6.167743 \\
\hline 565 & 1501000 & 796305059.6 & 8.901079475 & 6.176381 \\
\hline 116 & 1443922 & 766024246.7 & 8.884242516 & 6.159544 \\
\hline 555 & 1485698 & 788187098.3 & 8.896629322 & 6.171931 \\
\hline 111 & 1381371 & 732839917.7 & 8.865009117 & 6.14031 \\
\hline 111 & 1384576 & 734540222.7 & 8.866015582 & 6.141317 \\
\hline 507 & 861627 & 457107221.6 & 8.660018083 & 5.935319 \\
\hline 507 & 861627 & 457107221.6 & 8.660018083 & 5.935319 \\
\hline 510 & 859917 & 456200038.6 & 8.659155318 & 5.934457 \\
\hline 503 & 893314 & 473917693.6 & 8.675702923 & 5.951004 \\
\hline 132 & 1439114 & 763473524.1 & 8.882793981 & 6.158095 \\
\hline 523 & 1000286 & 530668089.9 & 8.724822973 & 6.000124 \\
\hline 505 & 945487 & 501596323.7 & 8.700354345 & 5.975656 \\
\hline 524 & 1256356 & 666517414.7 & 8.823811501 & 6.099113 \\
\hline 520 & 1082673 & 574375741.4 & 8.759196089 & 6.034497 \\
\hline
\end{tabular}




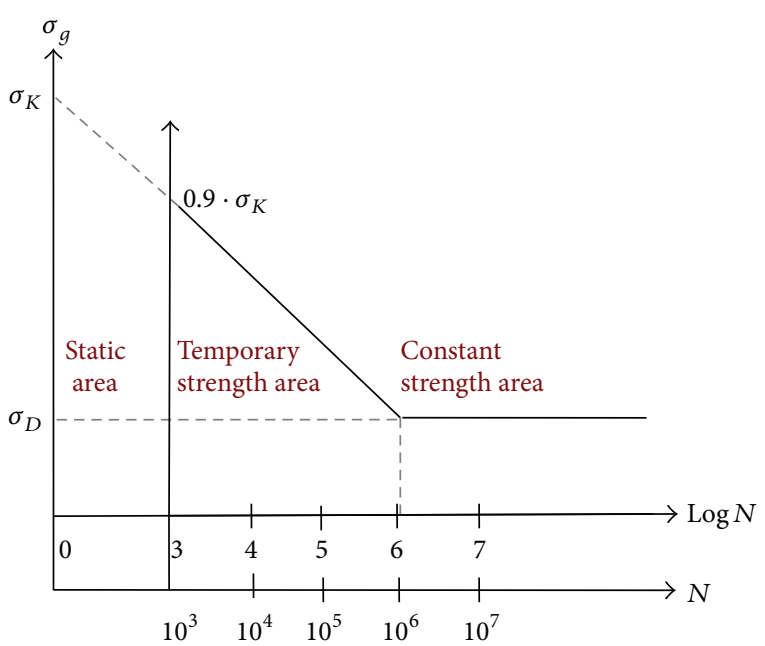

FIGURE 3: Stress-life diagram.

Derived life equations for $90 \%$ reliability in the case of TR-LRT:

$$
\log N=10.6653-8.5171 \frac{\sigma_{g}}{\sigma_{K \max }} .
$$

Derived life equations for $10 \%$ reliability in the case of TR-LRT:

$$
\log N=11.5913-9.546 \frac{\sigma_{g}}{\sigma_{K \min }} .
$$

\section{Integrating Vibration Effects to Logarithmic Life Equations}

Since the paper aims to point out the effect of vibration on life of the axle, the vibration measurements at different speeds $(30 \mathrm{~km} / \mathrm{h}, 40 \mathrm{~km} / \mathrm{h}$, and $50 \mathrm{~km} / \mathrm{h})$ have been performed. The experimental results have been used to determine the additional stresses arising from vibration in the critical section of the axle at these speeds.

4.1. Vibration Measurement and Setup. During the experiments the data acquisition process is controlled by means of a 6-channel dynamic signal analyzer pulse system of Bruel \& Kjaer (B\&K), Type 3560 C-E01 as shown in Figure 4. $\mathrm{B} \& \mathrm{~K} 4506 \mathrm{~B}$ and $4506 \mathrm{~B} 003$ type accelerometers are used to measure the output of the system (Figure 5). Technical properties of B\&K Type 4506 B 003 accelerometer are given in Table 6.

Measurements have been done for an ABB motor bogie of rail vehicle (vehicle number 514) which travels on ballasted track. The travelling speed of the rail vehicle has been set to $50 \mathrm{~km} / \mathrm{h}, 40 \mathrm{~km} / \mathrm{h}$, and $30 \mathrm{~km} / \mathrm{h}$. As a result of the measurements the displacement amplitudes of the axle (Figure 6) and the frequency and acceleration of the vibration measured from the axle (Figure 7) have been presented.

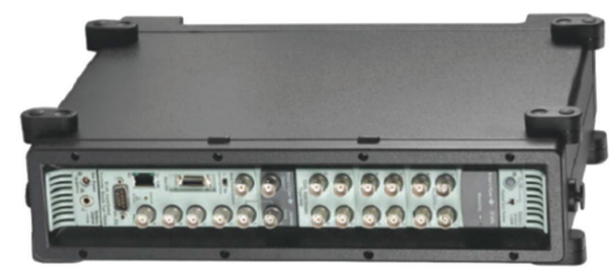

FIGURE 4: Six-channel dynamic signal analyzer pulse system (Type 3560 C-E01).

4.2. Additional Stress Resulted from Vibration on the Axle. As a result of measurements which have been performed for different speeds of the rail vehicle, RMS vertical vibration values as displacements $(\delta)$ have been obtained (Table 7$)$. Depending on the displacements of the axle and frequency, dynamic force $\left(F_{\text {dyn }}\right)$, bending moment $\left(M_{b}\right)$, and finally bending stress $\left(\left(\sigma_{b}\right)_{\mathrm{vib}}\right)_{g}$ which belongs to vibration have been calculated by means of equations given in Appendix section. The summarized parameters in Table 7 have been provided to find out additional stress resulted from vibration.

By considering the vibration effects a new equivalent stress of $\left(\sigma_{\mathrm{vib}}\right)_{\mathrm{eq}}=32.46 \mathrm{~N} / \mathrm{mm}^{2}$ has been obtained which is used for the derivation of new logarithmic life equations presented in the next subsection.

4.3. New Logarithmic Life Equations. It should be mentioned that the mean life and standard deviations are acquired as $\bar{N}_{l}=8.4185$ from (3) and $S_{N_{l}}=0.1161$ from (4) by predicating logarithmic dispersion in Table 2 while they are acquired as $\bar{N}_{l}=8.7728$ from (3) and $S_{N_{l}}=0.0962$ from (4) by considering logarithmic dispersion in Table 3.

Derived life equations for $90 \%$ reliability in the case of TR:

$$
\log N=10.5489-8.3877 \frac{\sigma_{g}}{\sigma_{K \max }} .
$$

Derived life equations for $10 \%$ reliability in the case of TR:

$$
\log N=11.6982-9.6647 \frac{\sigma_{g}}{\sigma_{K \min }} .
$$

Derived life equations for $90 \%$ reliability in the case of TR-LRT:

$$
\log N=11.0924-8.9916 \frac{\sigma_{g}}{\sigma_{K \max }} .
$$

Derived life equations for $10 \%$ reliability in the case of TR-LRT:

$$
\log N=12.2112-10.2347 \frac{\sigma_{g}}{\sigma_{K \min }} .
$$

Graphics which are drawn by using these equations have been illustrated in Figures 8 and 9. 


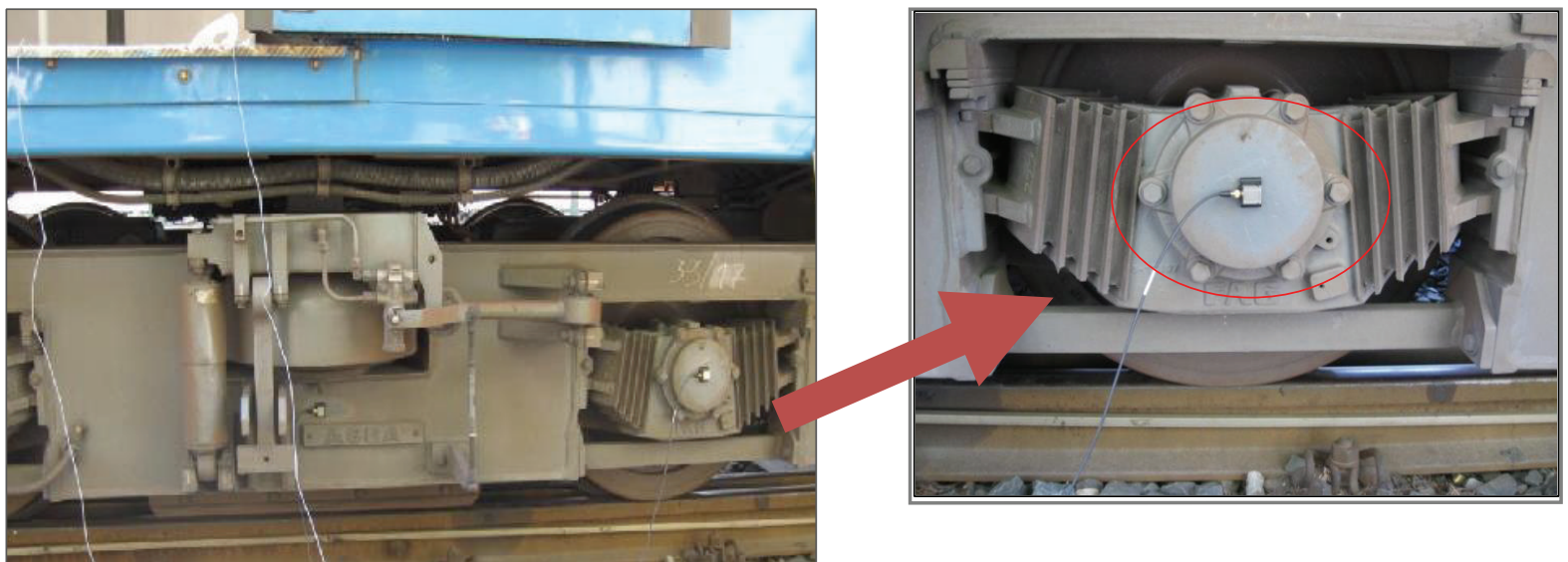

Figure 5: The accelerometer mounted on axle box.

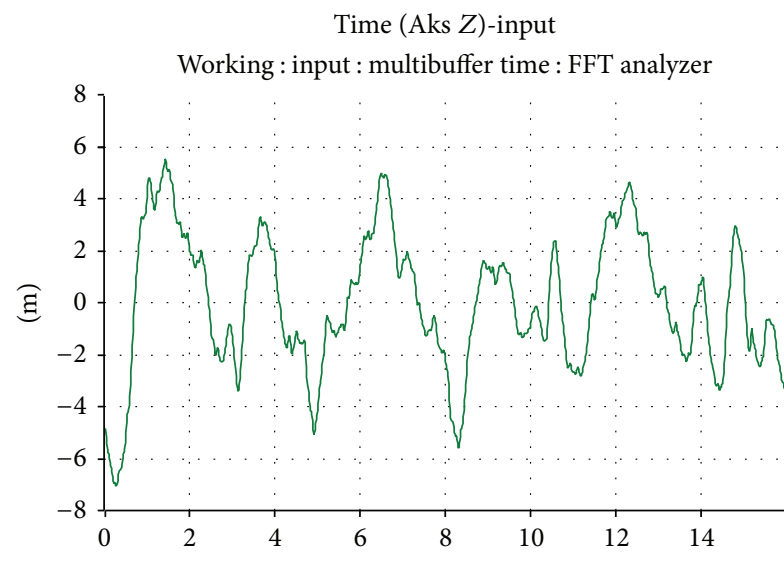

(s)

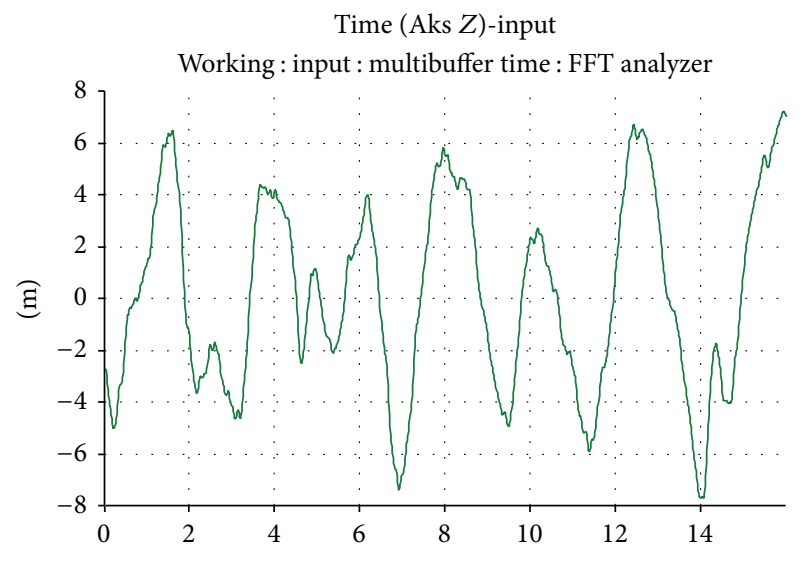

(s)

(a)

(b)

Time (Aks Z)-input

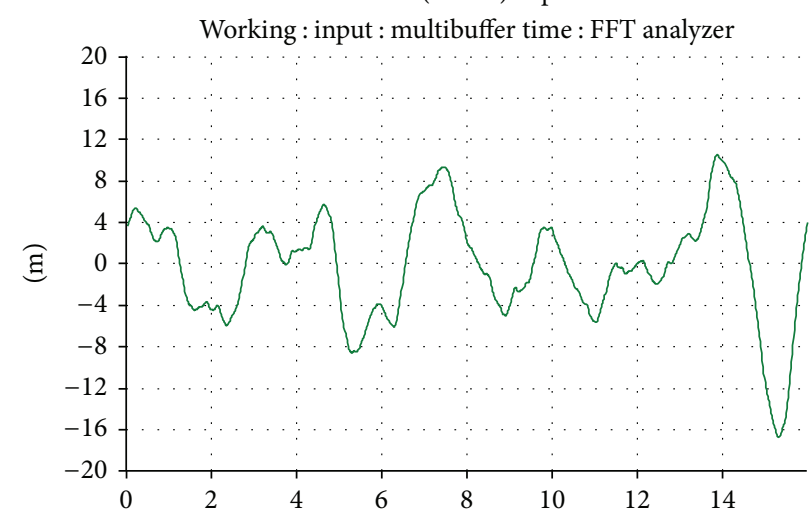

(s)

(c)

Figure 6: Measured displacement amplitudes of the axle for $V=50 \mathrm{~km} / \mathrm{h}(\mathrm{a}), V=40 \mathrm{~km} / \mathrm{h}(\mathrm{b})$, and $V=30 \mathrm{~km} / \mathrm{h}$ (c). 
Autospectrum (Aks $Z$ )-input

Working : input : multibuffer spectra : FFT analyzer

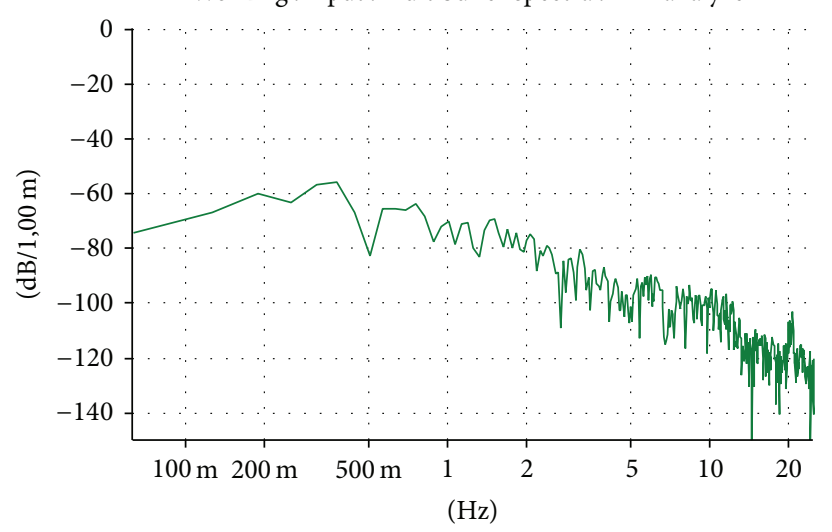

(a)

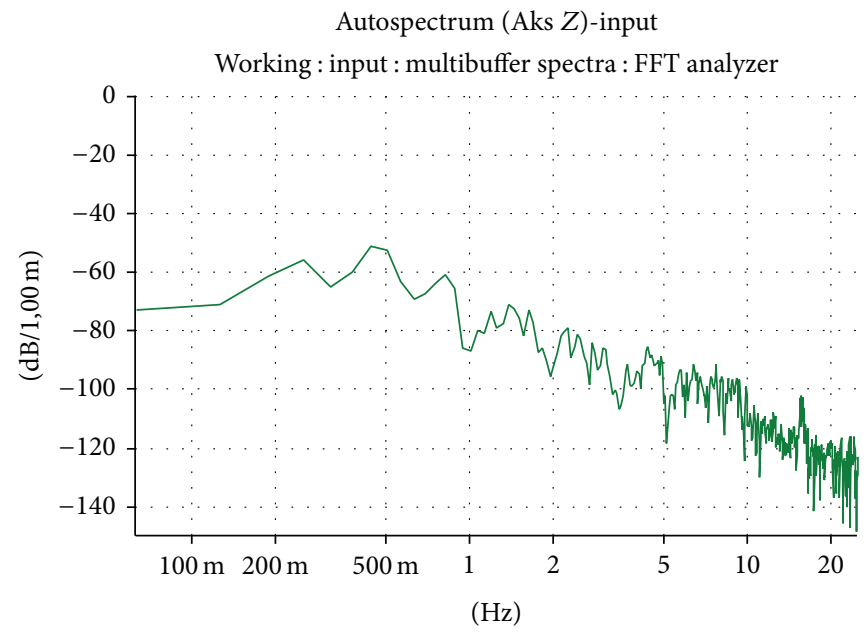

(b)

Autospectrum (Aks $Z$ )-input Working : input : multibuffer spectra : FFT analyzer

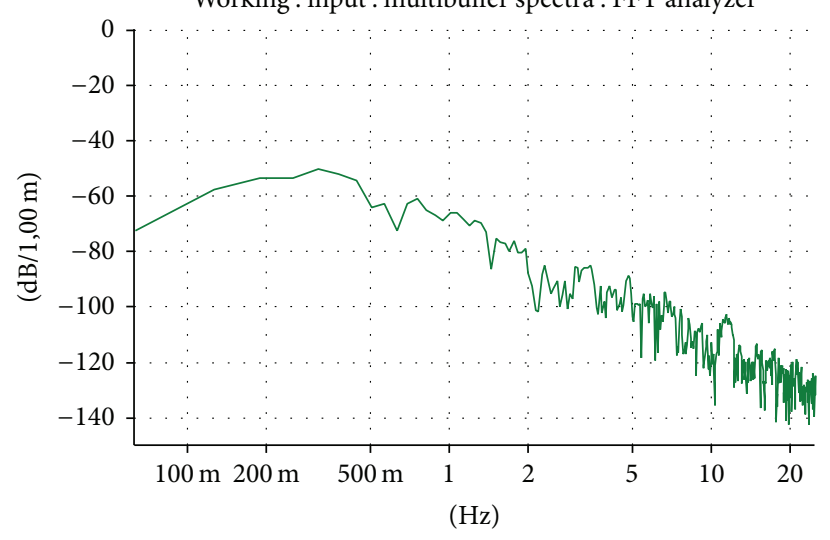

(c)

FiguRE 7: Frequency and acceleration of the vibration measured from the axle for $V=50 \mathrm{~km} / \mathrm{h}(\mathrm{a}), V=40 \mathrm{~km} / \mathrm{h}(\mathrm{b})$, and $V=30 \mathrm{~km} / \mathrm{h}(\mathrm{c})$.

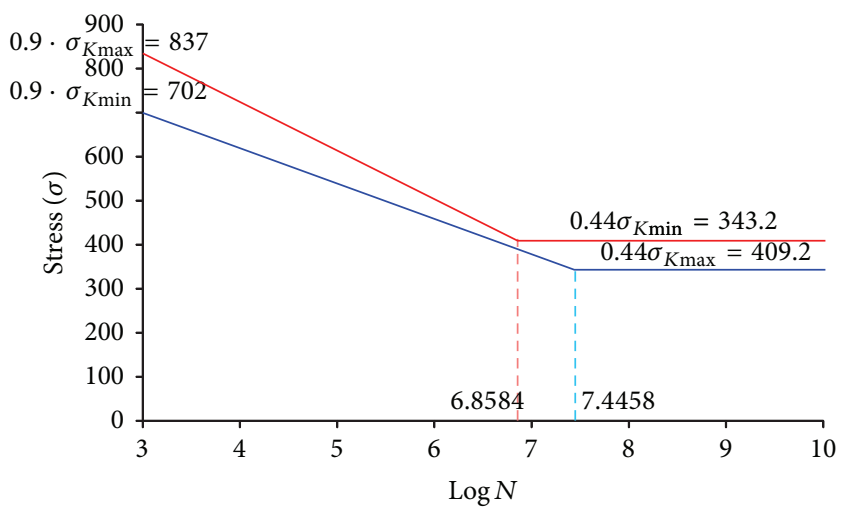

$x_{\min }: G 90$

FIGURE 8: TR: life-LogN.

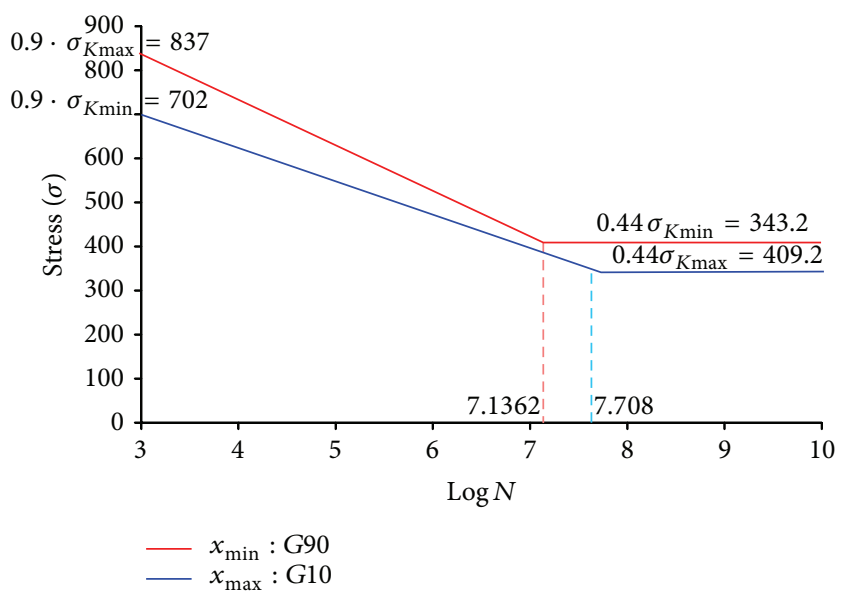

Figure 9: TR-LRT: life-LogN. 


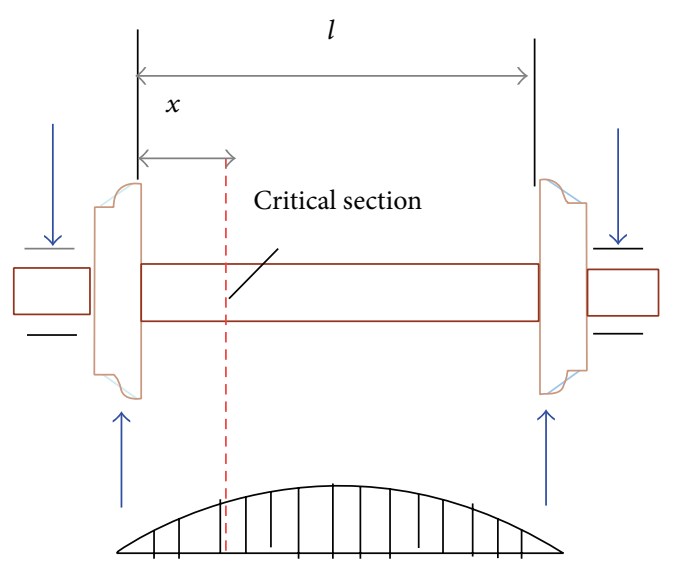

FIgURE 10: The bending stress in the critical section of the axle.

\section{Statistical Analysis and Discussion}

In the present section, the life values obtained with and without the vibration effects have been compared with each other for $90 \%$ and $10 \%$ reliability in the case of TR and TRLRT in Table 8. It should be noted that these life values are the results of derived logarithmic equations.

On the other side, real life values given in Table 1 have been presented statistically in Table 9 by considering $90 \%$ and $10 \%$ reliability.

The discrepancies between the real data and the results of the derived equations including the vibration effects are presented in Table 10.

\section{Conclusion}

The present paper examines the fractures of axles of rail vehicles that are operated by Istanbul Transportation Co. The logarithmic life equations have been derived for different cases where TR and TR-LRT are in operation. These equations have been obtained by means of real fracture data taking the related corporation.

Negative effects of vibrations on life of the axle have been pointed out by performing vibration measurements on the axle that run at different speeds and additional vibration induced bending stresses have been included in the calculations. Life of the axles has been calculated with $90 \%$ and $10 \%$ reliability and results have been compared to the real data.

In the case of TR the $90 \%$ reliability life of the axle has been found as $350.833 \mathrm{~km}$ whereas the real life value of the axle is $350.914 \mathrm{~km}$. In the case of TR-LRT, the $90 \%$ reliability life of the axle has been found as $840.428 \mathrm{~km}$ although the real life value is $841.397 \mathrm{~km}$.

By considering the effect of the vibration on the axle, the error margins in the calculation of $90 \%$ reliability life values of the axles are $0.023 \%(81 \mathrm{~km})$ and $0.11 \%(924 \mathrm{~km})$ for the cases of TR and LRT, respectively. Error margins in the calculation of $10 \%$ reliability life values of the axles are $0.023 \%(159 \mathrm{~km})$ and $0.092 \%(1363 \mathrm{~km})$ for TR and LRT, respectively.

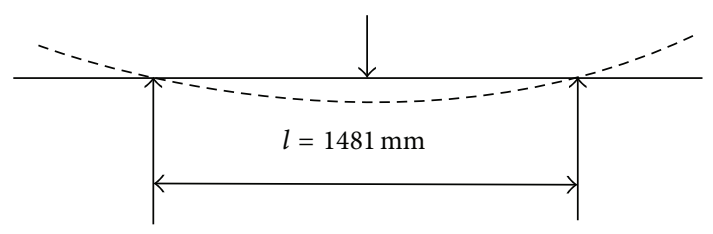

FIGURE 11: Static displacement on the axle.

Damage failure and life of the axles should be followed by performing periodic examinations which are determined by considering the calculated reliability life values as done in the present study. It is not possible to obtain longer life by keeping the same construction parameters of the axle such as material and radius.

The reason for creating additional, effective stresses on the axle by vibration is that the dynamic forces which are determined by considering the travel service percentages at different speeds are around the resonance area. The dynamic forces increase in the case of increasing the stiffness of the axle and dynamic displacements when regarding the parameters that affect the dynamic forces. By increasing the dynamic forces the stresses resulted from vibration will increase, so the life of the axle will be affected negatively.

\section{Appendices}

\section{A. Tables 1, 2, 3, 4, and 5}

The relation between load cycle and $\mathrm{km}$ used in tables and calculations has been given as the following equation:

$$
N_{k}=\frac{N \cdot \text { Perimeter }[\mathrm{m}]}{1000}[\mathrm{~km}]
$$

where perimeter $=\pi D_{0}[\mathrm{~mm}]$ and $D_{0}$ is the diameter of the wheel $(600 \mathrm{~mm})$.

\section{B. The Stress Calculation due to Vibration}

The bending moment at the critical section which is shown in Figure 10 has been calculated by using (B.1). Here, $M_{b}$ is the bending moment and $l(l=1481 \mathrm{~mm})$ is axle length shown in Figure 11. Also, dynamic force $\left(F_{\mathrm{dyn}}\right)$ and angular velocity relations have been given in (B.1) and (B.2), respectively:

$$
\begin{gathered}
F_{\mathrm{dyn}}=\left(k_{e}-m \omega^{2}\right) \delta \mathrm{dyn}, \\
\omega=\frac{v}{r}, \\
M_{b}=\frac{W \cdot x}{2}(l-x), \\
\frac{1}{\left(\sigma_{\mathrm{vib}}\right)_{\mathrm{eq}}}=\frac{C_{1}}{\left(\sigma_{\mathrm{vib}}\right)_{V=50}}+\frac{C_{2}}{\left(\sigma_{\mathrm{vib}}\right)_{V=40}}+\frac{C_{3}}{\left(\sigma_{\mathrm{vib}}\right)_{V=30}} .
\end{gathered}
$$


TABLE 4: The standard normal distribution table [18].

\begin{tabular}{|c|c|c|c|c|c|c|c|c|c|c|}
\hline$z_{\alpha}$ & .00 & .01 & .02 & .03 & .04 & .05 & .06 & .07 & .08 & .09 \\
\hline 0.0 & .5000 & .4960 & .4920 & .4880 & .4840 & .4801 & .4761 & .4721 & .4681 & .4641 \\
\hline 0.1 & .4602 & .4562 & .4522 & .4483 & .4443 & .4404 & .4364 & .4325 & .4286 & .4247 \\
\hline 0.2 & .4207 & .4168 & .4129 & .4090 & .4052 & .4013 & .3974 & .3936 & .3897 & .3859 \\
\hline 0.3 & .3821 & .3783 & .3745 & .3707 & .3669 & .3632 & .3594 & .3557 & .3520 & .3483 \\
\hline 0.4 & .3446 & .3409 & .3372 & .3336 & .3300 & .3264 & .3228 & .3192 & .3156 & .3121 \\
\hline 0.5 & .3085 & .3050 & .3015 & .2981 & .2946 & .2912 & .2877 & .2843 & .2810 & .2776 \\
\hline 0.6 & .2743 & .2709 & .2676 & .2643 & .2611 & .2578 & .2546 & .2514 & .2483 & .2451 \\
\hline 0.7 & .2420 & .2389 & .2358 & .2327 & .2296 & .2266 & .2236 & .2206 & .2177 & .2148 \\
\hline 0.8 & .2119 & 2090 & .2061 & .2033 & .2005 & .1977 & 1949 & .1922 & .1894 & .1867 \\
\hline 0.9 & .1841 & .1814 & .1788 & .1762 & .1736 & .1711 & .1685 & .1660 & .1635 & .1611 \\
\hline 1.0 & .1587 & .1562 & .1539 & .1515 & .1492 & .1469 & .1446 & .1423 & .1401 & .1379 \\
\hline 1.1 & .1357 & .1335 & .1314 & .1292 & .1271 & .1251 & .1230 & .1210 & .1190 & .1170 \\
\hline 1.2 & .1151 & .1131 & .1112 & .1093 & .1075 & .1056 & .1038 & .1020 & .1003 & .0985 \\
\hline 1.3 & .0968 & .0951 & .0934 & .0918 & .0901 & .0885 & .0869 & .0853 & .0838 & .0823 \\
\hline 1.4 & .0808 & .0793 & .0778 & .0764 & .0749 & .0735 & .0721 & .0708 & .0694 & .0681 \\
\hline 1.5 & .0668 & .0655 & .0643 & .0630 & .0618 & .0606 & .0594 & .0582 & .0571 & .0559 \\
\hline 1.6 & .0548 & .0537 & .0526 & .0516 & .0505 & .0495 & .0485 & .0475 & .0465 & .0455 \\
\hline 1.7 & .0446 & .0436 & .0427 & .0418 & .0409 & .0401 & .0392 & .0384 & .0375 & .0367 \\
\hline 1.8 & .0359 & .0351 & .0344 & .0336 & .0329 & .0322 & .0314 & .0307 & .0301 & .0294 \\
\hline 1.9 & .0287 & .0281 & .0274 & .0268 & .0269 & .0256 & .0250 & .0244 & .0239 & .0233 \\
\hline 2.0 & .0228 & .0222 & .0217 & .0212 & .0207 & .0202 & .0197 & .0192 & .0188 & .0183 \\
\hline 2.1 & .0179 & .0174 & .0170 & .0166 & .0162 & .0158 & .0154 & .0150 & .0146 & .0143 \\
\hline 2.2 & .0139 & .0136 & .0132 & .0129 & .0125 & .0122 & .0119 & .0116 & .0113 & .0110 \\
\hline 2.3 & .0107 & .0104 & .0102 & .0099 & .0096 & .0094 & .0091 & .0089 & .0087 & .0084 \\
\hline 2.4 & .0082 & .0080 & .0078 & .0075 & .0073 & .0071 & .0069 & .0068 & .0066 & .0064 \\
\hline 2.5 & .0062 & .0060 & .0059 & .0057 & .0055 & .0054 & .0052 & .0051 & .0049 & .0048 \\
\hline 2.6 & .0047 & .0045 & .0044 & .0043 & .0041 & .0040 & .0039 & .0038 & .0037 & .0036 \\
\hline 2.7 & .0035 & .0034 & .0033 & .0032 & .0031 & .0030 & .0029 & .0028 & .0027 & .0026 \\
\hline 2.8 & .0026 & .0025 & .0024 & .0023 & .0023 & .0022 & .0021 & .0020 & .0020 & .0019 \\
\hline 2.9 & .0019 & .0018 & .0017 & .0017 & .0016 & .0016 & .0015 & .0015 & .0014 & .0014 \\
\hline
\end{tabular}

TABLE 5: Life formulas by considering normal distribution table [18].

\begin{tabular}{lcc}
\hline Reliability (\%) & $z_{\alpha}$ & $G$ \\
\hline 10 & +1.28 & $N=+1.28 S_{N}+\bar{N}$ \\
90 & -1.28 & $N=-1.28 S_{N}+\bar{N}$ \\
\hline
\end{tabular}

TABLE 6: Technical properties of B\&K Type 4506 B 003 accelerometer.

\begin{tabular}{lccc}
\hline 14506 B 003 & $X$ & $Y$ & $Z$ \\
\hline Frequency range $[\mathrm{kHz}]$ & & & \\
$\quad$ Amplitude $( \pm 10 \%)$ & $0.3-0.4$ & $0.3-0.2$ & $0.3-2$ \\
Phase $( \pm 5)$ & $2-2.5$ & $2-2.5$ & $2-2.5$ \\
Resonance frequency $[\mathrm{kHz}]$ & 14 & 7 & 7 \\
\hline
\end{tabular}

\section{Nomenclature}

TR: Tramway

LRT: Light rail vehicle

$N$ : Life (load cycle)

$S: \quad$ Stress
$N_{\mathrm{km}}: \quad$ Life $(\mathrm{km})$

$N_{\text {eq }}: \quad$ Equivalent life

$\log N$ : $\quad$ Logarithmic life

$\log N_{\text {Realistic }}$ : Logarithmic life values obtained by considering the reports of Istanbul Transportation Co.

$\log N_{\text {Calculation }}$ : Logarithmic life values obtained by performing calculations as a result of applying cumulative damage theory

$(\log N)_{G 10}$ : Logarithmic life by considering reliability for $10 \%$

$(\log N)_{G 90}: \quad$ Logarithmic life by considering reliability for $90 \%$

$\sigma: \quad$ Stress $\left(\mathrm{N} / \mathrm{mm}^{2}\right)$

$\sigma_{\text {eq }}: \quad$ Equivalent stress $\left(\mathrm{N} / \mathrm{mm}^{2}\right)$

$\sigma_{K}: \quad$ Ultimate stress $\left(\mathrm{N} / \mathrm{mm}^{2}\right)$

$\sigma_{K \max }: \quad \quad$ Maximum ultimate stress for $34 \mathrm{CrNiMo6}$ $\left(930 \mathrm{~N} / \mathrm{mm}^{2}\right)$

$\sigma_{K \min }: \quad$ Minimum ultimate stress for $34 \mathrm{CrNiMo6}$ $\left(780 \mathrm{~N} / \mathrm{mm}^{2}\right)$

$\sigma_{D}: \quad$ Constant strength stress $\left(\mathrm{N} / \mathrm{mm}^{2}\right)$ 
TABLE 7: Additional stresses resulted from vibration and the related parameters.

\begin{tabular}{|c|c|c|c|c|c|}
\hline $\begin{array}{l}\text { Speed } \\
V \\
{[\mathrm{~km} / \mathrm{h}]}\end{array}$ & $\begin{array}{c}\text { Amplitude } \\
\delta \\
{[\mathrm{mm}]}\end{array}$ & $\begin{array}{c}\text { Frequency } \\
\omega \\
{[1 / \mathrm{sn}]}\end{array}$ & $\begin{array}{c}\text { Dynamic force } \\
F_{\text {dyn }} \\
{[\mathrm{N}]}\end{array}$ & $\begin{array}{c}\text { Bending moment } \\
M_{b} \\
{[\mathrm{Nmm}]}\end{array}$ & $\begin{array}{c}\text { Bending stress } \\
\left(\left(\sigma_{b}\right)_{\mathrm{vib}}\right)_{g} \\
{\left[\mathrm{~N} / \mathrm{mm}^{2}\right]}\end{array}$ \\
\hline 50 & 0.00260 & 46.29 & 13.35 & 650429.32 & 12.77 \\
\hline 40 & 0.00372 & 37.03 & 44.32 & 2159004.48 & 42.39 \\
\hline 30 & 0.0052 & 27.77 & 89.38 & 4354057.32 & 85.49 \\
\hline
\end{tabular}

TABLE 8: Statistical calculations.

\begin{tabular}{|c|c|c|c|c|}
\hline \multirow[t]{2}{*}{ Life } & \multicolumn{2}{|c|}{$\begin{array}{c}\sigma=220.24 \mathrm{~N} / \mathrm{mm}^{2} \\
\text { (without vibration effect) }\end{array}$} & \multicolumn{2}{|c|}{$\begin{array}{c}\sigma=252.7 \mathrm{~N} / \mathrm{mm}^{2} \\
(\text { with vibration effect) }\end{array}$} \\
\hline & $\begin{array}{l}N_{\text {Calculation }} \\
\text { [load cycle] }\end{array}$ & $\begin{array}{c}N_{\text {Calculation }} \\
{[\mathrm{km}]}\end{array}$ & $\begin{array}{c}N_{\text {Calculation }} \\
\text { [load cycle] }\end{array}$ & $\begin{array}{c}N_{\text {Calculation }} \\
{[\mathrm{km}]}\end{array}$ \\
\hline \multicolumn{5}{|c|}{$90 \%$ reliability } \\
\hline TR & $10^{8.5625}$ & 688336 & $10^{8.2698}$ & 350833 \\
\hline TR-LRT & $10^{8.9631}$ & 1731414 & $10^{8.6492}$ & 840428 \\
\hline \multicolumn{5}{|c|}{$10 \%$ reliability } \\
\hline TR & $10^{8.9722}$ & 1768076 & $10^{8.5670}$ & 695506 \\
\hline TR-LRT & $10^{9.3234}$ & 3969181 & $10^{8.8955}$ & 1481838 \\
\hline
\end{tabular}

TABLE 9: Statistical real life data.

\begin{tabular}{lcc}
\hline Life & & Real life values (Table 1) \\
\hline $90 \%$ reliability & $N_{\text {Real }}[$ load cycle $]$ & $N_{\text {Real }}[\mathrm{km}]$ \\
TR & $10^{8.2699}$ & 350914 \\
TR-LRT & $10^{8.6497}$ & 841397 \\
$10 \%$ reliability & & 695666 \\
TR & $10^{8.5671}$ & 1483204 \\
TR-LRT & $10^{8.8959}$ & \\
\hline
\end{tabular}

TABLE 10: Relative errors.

\begin{tabular}{lcccc}
\hline Logarithmic life equations & Case & $\log N_{\text {Real }}$ & $\log N_{\text {Calculation }}$ & $H_{R}=\frac{\left(N_{\text {Realistic }}-N_{\text {Calculation }}\right)}{N_{\text {Re alistic }}}$ \\
\hline$(\log N)_{G 90}=10.5489-8.3877 \frac{\sigma_{g}}{\sigma_{K \max }}$ & TR & 8.2699 & 8.2698 & $0.023 \%(81 \mathrm{~km})$ \\
\hline$(\log N)_{G 90}=11.0924-8.9916 \frac{\sigma_{g}}{\sigma_{K \max }}$ & TR-LRT & 8.6497 & 8.6492 & $0.11 \%(924 \mathrm{~km})$ \\
\hline$(\log N)_{G 10}=11.6982-9.6647 \frac{\sigma_{g}}{\sigma_{K \min }}$ & TR & 8.5671 & 8.5670 & $0.023 \%(159 \mathrm{~km})$ \\
\hline$(\log N)_{G 10}=12.2112-10.2347 \frac{\sigma_{g}}{\sigma_{K \min }}$ & TR-LRT & 8.8959 & 8.8955 & $0.092 \%(1363 \mathrm{~km})$ \\
\hline
\end{tabular}

$$
\begin{array}{ll}
\left(\left(\sigma_{b}\right)_{\mathrm{vib}}\right)_{g}: & \text { Bending stress }\left(\mathrm{N} / \mathrm{mm}^{2}\right) \\
M_{b}: & \text { Bending moment }(\mathrm{Nmm}) \\
F_{\text {dyn }}: & \text { Dynamic force }(\mathrm{N}) \\
\Omega: & \text { Frequency }(1 / \mathrm{sn}) \\
\delta: & \text { Amplitude }(\mathrm{mm}) \\
V: & \text { Speed }(\mathrm{km} / \mathrm{h})
\end{array}
$$

$\bar{N}: \quad$ Mean life

$\bar{\sigma}: \quad$ Mean stress

S: $\quad$ Standard deviation

$z_{\alpha}$ : Standard variable

$H_{R}$ : Relative error

RMS: Root mean square. 


\section{Conflict of Interests}

The authors declare that there is no conflict of interests regarding the publication of this paper.

\section{Acknowledgments}

This work was supported by Istanbul Transportation Co., Turkey. Authors thank Istanbul Transportation Co. for providing data and the reviewers for their valuable comments.

\section{References}

[1] V. Grubisic and G. Fischer, "Procedure for reliable durability validation of train axles," Materialwissenschaft und Werkstofftechnik, vol. 37, no. 12, pp. 973-982, 2006.

[2] S. Alfi, F. Braghin, and S. Bruni, "Numerical and experimental evaluation of extreme wheel-rail loads for improved wheelset design," in Proceedings of the 20th International Association for Vehicle System Dynamics Symposium (IAVSD '07), Berkeley, Calif, USA, 2007.

[3] B. H. Park, N. Po Kim, J. Seok Kim, and K. Yong Lee, "Optimum design of tilting bogie frame in consideration of fatigue strength and weight," Vehicle System Dynamics, vol. 44, no. 12, pp. 887901, 2006.

[4] J. Evans and M. Berg, "Challenges in simulation of rail vehicle dynamics," Vehicle System Dynamics, vol. 47, no. 8, pp. 10231048, 2009.

[5] S. Dietz, K. Knothe, and W. Kortüm, "Fatigue life simulations applied to railway bogies," in Proceedings of the 4th International Conference on Railway Bogies and Running Gears, Budapest, Hungary, 1998.

[6] S. Lee, R. Kang, and K. Rho, Fatigue Analysis of High Speed Passenger Train under Extreme Operating Conditions, Korea Institute of Machinery \& Materials.

[7] C. Locovei, A. Raduta, M. Nicora, and L. R. Cucuruz, "Analysis of a fatigue fracture of tank wagon railway axles," in Proceedings of the 3rd WSEAS International Conference on Finite DifferencesFinite Elements-Finite Volumes-Boundary Elements, pp. 978960, 2010.

[8] S. G. Abel and N. K. Cooperrider, "An equivalent linearization algorithm for nonlinear system limit cycle analysis," Journal of Dynamic Systems, Measurement and Control, vol. 107, no. 2, pp. 117-122, 1985.

[9] J. K. Hedrick and A. V. Arslan, "Nonlinear analysis of rail vehicle forced lateral response and stability," ASME Journal of Dynamic Systems, Measurement and Control, vol. 101, no. 3, pp. 230-237, 1979.

[10] R. R. I. Huilgol, "Hopf-Friedrichs bifurcation and the hunting of railway axle," Quarterly of Applied Mathematics, vol. 36, no. 1, pp. 85-94, 1978.

[11] A. S. Watson and K. Timmis, "A method of estimating railway axle stress spectra," Engineering Fracture Mechanics, vol. 78, no. 5, pp. 836-847, 2011.

[12] M. Ognjanovic, A. Simonovic, M. Ristivojevic, and T. Lazovic, "Research of rail traction shafts and axles fractures towards impact of service conditions and fatigue damage accumulation," Engineering Failure Analysis, vol. 17, no. 7-8, pp. 1560-1571, 2010.

[13] M. Novosad, R. Fajkoš, B. Řeha, and R. Řezníček, "Fatigue tests of railway axles," in Proceedings of the 10th International Fatigue Congress (FATIGUE '10), vol. 2, pp. 2259-2268, June 2010.
[14] EN13103, "Railway application-Wheelsets and bogies-Nonpowered axles-Design method".

[15] "Railway application-wheelsets and bogies-powered axlesdesign method," EN 13104, 2009.

[16] M. Bayraktar, N. Tahrali, and R. Guclu, "Reliability and fatigue life evaluation of railway axles," Journal of Mechanical Science and Technology, vol. 24, no. 3, pp. 671-679, 2010.

[17] A. Fatemi and L. Yang, "Cumulative fatigue damage and life prediction theories: a survey of the state of the art for homogeneous materials," International Journal of Fatigue, vol. 20, no. 1, pp. 9-34, 1998.

[18] N. Tahrali and F. Dikmen, Reliability and Life Calculations for Machine Elements, Yildiz Technical University Press, 2004.

[19] G. E. Saatci and N. Tahrali, "Cumulative failure theories and life evaluation for fatigue crack," Journal of Aeronautics and Space Technologies, vol. 1, pp. 33-39, 2003.

[20] G. E. Saatci and N. Tahrali, "Cumulative failure theories and the application to transmission elements," Journal of Aeronautics and Space Technologies, vol. 1, pp. 21-30, 2003.

[21] J. A. Collins, Failures of Materials in Mechanical Design, John Wiley \& Sons, New York, NY, USA, 2nd edition, 1993.

[22] G. E. Saatci, The examination of cumulative failure theories for dynamic fractures and application to transmission elements of GTD model $4 \times 4$ military vehicle [Ph.D. thesis], Yildiz Technical University, 2002.

[23] M. Akkurt and M. Kent, Machine Elements, vol. 1, Istanbul Technical University Press, 1975.

[24] J. J. Xiong and R. A. Shenoi, Fatigue and Fracture Reliability Engineering, Springer, 2011.

[25] M. Bayraktar, Dynamic analysis of rail vehicle axles [Ph.D. thesis], Yildiz Technical University, Istanbul, Istanbul, Turkey, 2010. 


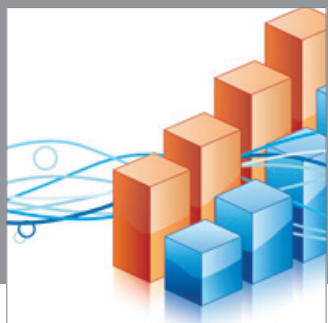

Advances in

Operations Research

mansans

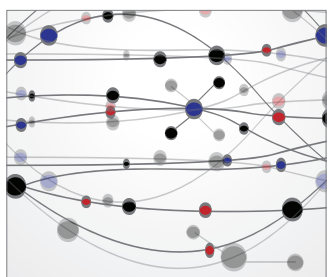

The Scientific World Journal
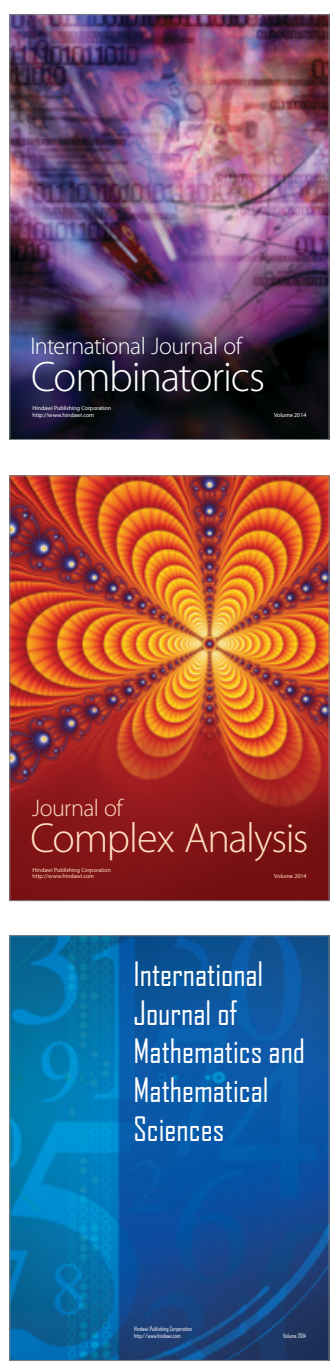
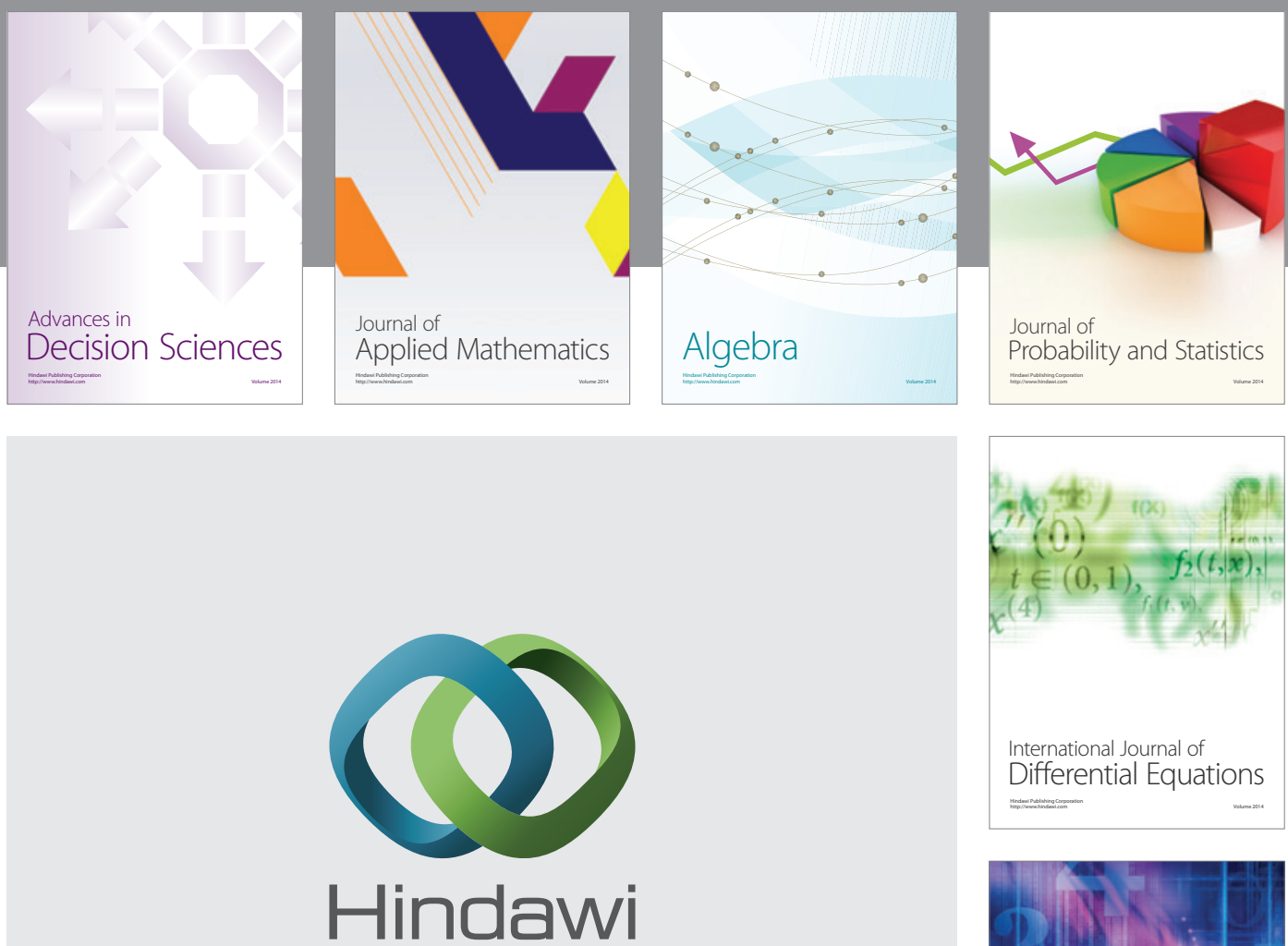

Submit your manuscripts at http://www.hindawi.com
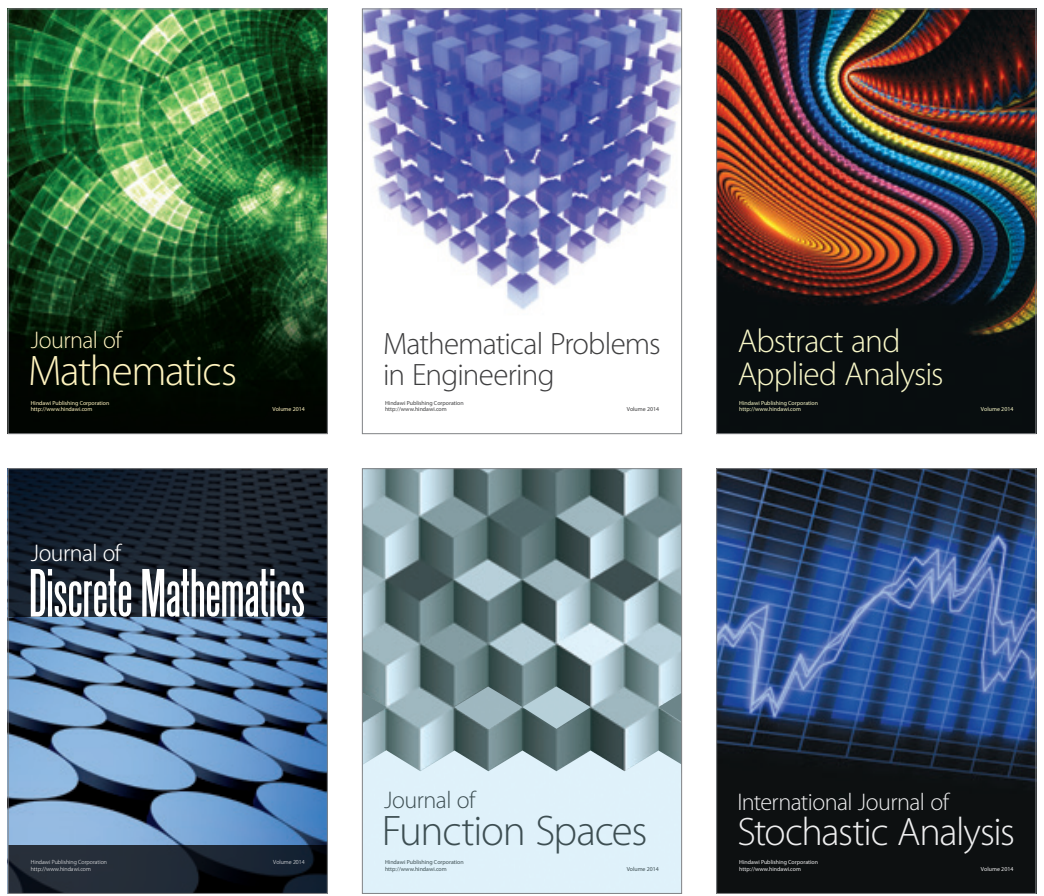

Journal of

Function Spaces

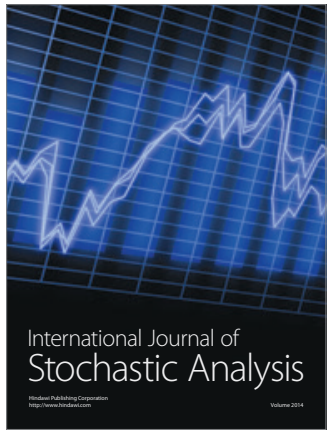

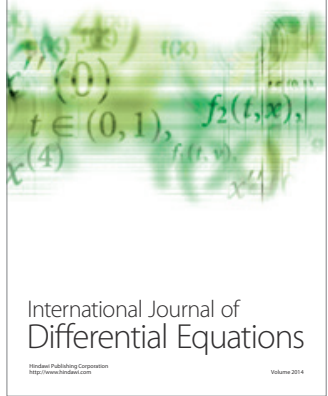
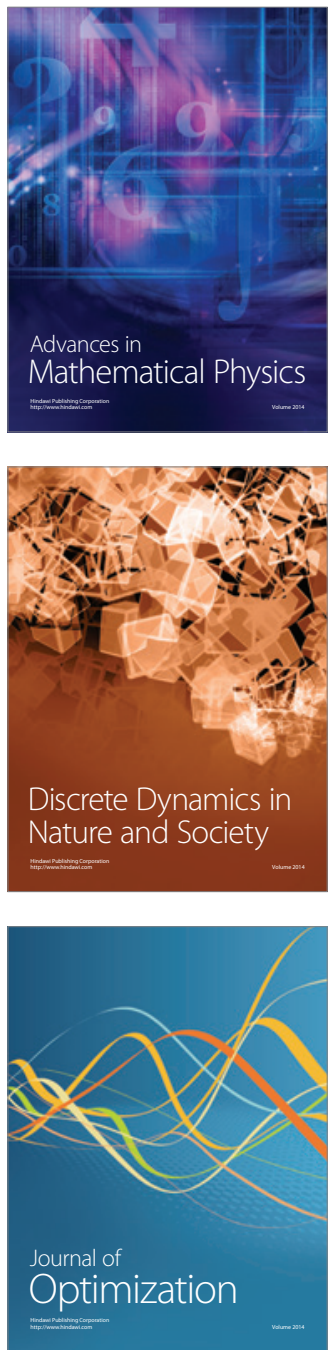